Kasim A Mohammad BDS, MSc (Assist Lect)

\section{Effect of Type of Light Curing Unit on Shear Bond Strength of Resin Composite.}

\author{
Department of Conservative Dentistry \\ College of Dentistry, University of Mosul
}

\begin{abstract}
Aims: To compare the shear bond strength (SBS) of composite bonded to dentin cured by three light curing units (LCUs), which are quartz tungsten halogen (QTH) and two types of light emitting diode (LED) machines. Materials and Methods: Buccal dentin of 90 upper premolars was exposed, prior to restorative procedure. Samples divided into 3 groups, restoration of each group cured by Astralis 5 [Austria], Top Light, [Taiwan] and Ultradent [USA]. Each group further subdivided into three subgroups. After bonding application, each subgroup of every group restored by one of 3 composites: Point $4^{\mathrm{TM}}$, Tetric and Degufill mineral. Composite applied and cured for 40 seconds. Samples thermocycled and loaded at tooth-composite interface. Results: Analysis of variance (ANOVA) with significance $p \leq 0.05$ followed by Duncan Multiple Range Test, showed that SBS of subgroups that cured by Ultradent $\left(400 \mathrm{~mW} / \mathrm{cm}^{2}\right)$ was significantly higher than Astralis $5\left(405 \mathrm{~mW} / \mathrm{cm}^{2}\right)$ and Top Light $\left(141 \mathrm{~mW} / \mathrm{cm}^{2}\right)$. The SBS of Astralis 5 was significantly higher than Top Light. No significant differences found among subgroups those cured by same LCU. Conclusions: Shear bond strength of resin composite bonded to dentin is directly proportional with the light intensity. However, better result obtained by a high intensity LEDs compared with an equivalent intensity QTH-LCUs.

Key Words: Light emitting diode, composite, shear bond strength.
\end{abstract}

Mohammad KA. Effect of Type of Light Curing Unit on Shear Bond Strength of Resin Composite. AlRafidain Dent J. 2007; 7 (SpIss): 10S-17S

Received: 9/8/2006

Sent to Referees: $13 / 8$ /2006

Accepted for Publication: 21/11 /2006

\section{INTRODUCTION}

Visible light curing materials includeing resin composite, resin modified glass ionomers, cavity liners, fissure sealants, dentin primers, bonding agents and luting agents are widely used in dentistry ${ }^{(1)}$.

The efficiency of radiation source for photo polymerization has thus become increasingly important in daily clinical conditions. The traditionally used unit for polymerization of composite is quartz tungsten halogen (QTH) light curing unit (LCU). But, unfortunately they have some specific drawbacks including the reduction of light out-put with the time ${ }^{(1)}$, the halogen lamp and reflector may deteriorate over time due to the light operating temperatures and significant quality of heat produced during the operating cycle, these result in reducetion of curing effectiveness of QTH-LCU over time ${ }^{(2)}$, in addition to hazard of pulpal damage as $5.5^{\circ} \mathrm{C}$ increase in the pulpal temperature may cause irreversible damage of teeth pulps ${ }^{(3)}$. The reduction of light intensity due to the long usage of QTHLCU was reported and well known, in fact light intensity decreases with time even with a short radiation period ${ }^{(1)}$.

Development of dental equipment including light curing technologies have led to the invention of new curing units like blue super bright light emitting diode (LED) unit. Its principally developed to operate at $470 \mathrm{~nm}$ wavelength as an alternative to QTH-LCU ${ }^{(4)}$.

A number of studies had addressed the application of LED technology to cure dental materials, some reported regarding the light intensities of these light curing units (LCUs) ${ }^{(5-7)}$, or measuring the depth of cure or mechanical properties of cured composite exposed to these LCUs ${ }^{(8-12)}$. However the light intensities were measured using various types of commercial dental radiometers and no study has reported the light intensities measured using radiometer confirming to ISO standard (ISO TS 10650, 1999). Dental radiometers can't accurately evaluate light intensity, because sensitivity to the intensity varies with the wavelength and different light sources that have different spectral distribution ${ }^{(5)}$. 
Adequate polymerization of resin composite is considered to be a very important factor in obtaining adequate physical properties, and that is closely related to the degree of conversion of this material ${ }^{(13,14)}$.

Higher values of the degree of conversion and superior mechanical and physical properties can be achieved by high intensity lights, but they produce higher contraction strain rates due to shrinkage during polymerization of the composite ${ }^{(15)}$. Higher irradiation heat produced by LCUs also increasing contraction strain due to polymerization reaction acceleration ${ }^{(16,8)}$. Thus compromise the formation of an adequate adhesive bond between the composite and the tooth ${ }^{(17)}$.

The aim of this study was to compare shear bond strength (SBS) of composite bonded to dentin cured by three light curing units (LCUs) which are quartz tungsten halogen (QTH) and two types of light emitting diode (LED) machines (two different intensities).

\section{MATERIALS AND METHODS}

Two kindsof LCUs: QTH-LCUand LED (low and high intensities) were used. QTHLCU (Astralis 5, Vivadent, Austria). Low intensity LED (Top Light, Taiwan). High intensity LED (Ultradent, South Jordan, Utah 84095 USA).

Light intensity of each curing unit was measured using a radiometer (CROMATEST 7041, Curing Radiometer, Germany). The recorded light intensity values were as follow; QTH-LCU (405 mW/ $\mathrm{cm}^{2}$ ), LED "Top light" (141 $\left.\mathrm{mW} / \mathrm{cm}^{2}\right)$, LED "Ultradent"(400 mW/cm²), Table (1).

Three kinds of commercially available light cured composite materials were used: Point $4^{\mathrm{TM}}$ (Kerr), Tetric (Vivadent) and Degufill mineral (Degussa) in addition to self etching primer bonding agent (Clearfil), Table (2). The same shade (A2) was selected for all types of composite used in this study.

Ninety sound upper premolars extracted for orthodontic reasons were collected, cleaned, polished and stored in distilled water, used in this study. Roots of teeth were cut and discarded, then each crown was embedded in self-cure acrylic resin (Major Repair 2, 10024 Moncalieri, Italy), within cylindrical plastic tube $(2 \times 2 \mathrm{~cm})$ in such away that palatal and middle third were embedded within acrylic leaving the buccal third extruded out of acrylic and above the level of plastic ring rim to enable subsequent grinding, restorative materials application and testing. After that, Buccal surface of each tooth was grinded to remove buccal enamel and exposing dentin at least $4 \mathrm{~mm}$ diameter at middle third of tooth using 600 grit abrasive carbide papers mounted on grinding wheel of rotary pregrinder machine (Metaserv, Surry, England) with copious amount of water to create standardized dentin surface ${ }^{(18)}$.

Before application of the restorative materials, bonding agent applied according to manufacturer instructions and cured for 20 seconds with the tip of curing unit being perpendicular on the buccal surface with distance of $1 \mathrm{~mm}$ that controlled by using Teflon spacer which was a Teflon plate of $2 \times 4 \mathrm{~cm}$ and $1 \mathrm{~mm}$ thickness with a $5 \mathrm{~mm}$ diameter hole at the center of the plate in order not to interfere with the light beam irradiating the $4 \mathrm{~mm}$ diameter of exposed dentin, on the other hand this 5 $\mathrm{mm}$ hole was smaller than the tip of curing units, so keeping the tip constantly $1 \mathrm{~mm}$ distant from dentin.

Samples were divided into 3 groups (30 samples for each group), then each group further subdivided into 3 subgroups (10 samples for each subgroup) and restored according to following procedure:

First subgroup of each group restored with Point $4^{\mathrm{TM}}$ composite, second subgroup of each group restored with Tetric composite, and third subgroup of each group restored with Degufill mineral composite. Restorative materials applied by the aid of a Teflon split mold with cylindrical cavity of $4 \mathrm{~mm}$ in diameter and $3 \mathrm{~mm}$ thickness, which perfectly adjusted on the exposed dentin. Composite applied by two increments of $1.5 \mathrm{~mm}$ thickness for each, this procedure was guided by the thickness of split mold which is already composed of two layers of $1.5 \mathrm{~mm}$ for each layer as shown in Figure (1).

Approximation of the two parts of first layer of the split mold over the exposed dentin will provide a cylindrical space of $4 \mathrm{~mm}$ diameter and $1.5 \mathrm{~mm}$ depth (Figure 1A). 
First composite increment applied and cured for 40 seconds, then two parts of second layer of split mold approximated to each other creating a cylindri-cal space of $4 \mathrm{~mm}$ diameter and $1.5 \mathrm{~mm}$ depth continuous with the first space, at (Figure 1B). The second composite increment applied over the first one and cured for 40 seconds (as recommended by manufacturers). The three subgroups of first group cured by QTH-LCU, the three subgroups of second group cured by low intensity LED (Top light), and the three subgroups of third group cured by the higher intensity LED (Ultradent). Then samples thermocycled in a water bath for 300 times at a temperature $\left(5 \pm 2-55 \pm 2{ }^{\circ} \mathrm{C}\right)$ with a dwell time of 30 seconds for each cycle, ${ }^{(19)}$ then stored in tap water for 24 hours. After that the bond strength between tooth and composite was measured by using Universal Testing Machine (Soil Test Co. Inc., USA). The samples grasped by a holder that hold the plastic ring horizontally, so making the tooth-restoration interface vertical to the floor, then the interface between dentin surface and the core of composite subjected to a load with stainless steel knife edge head at a cross head speed of $1 \mathrm{~mm} /$ minute till failure occurred (Figure 2) ${ }^{(18)}$. The loads required to produce failure were recorded, calculated and statistically analyzed.

Table (1): Curing Units Used with Their Light Intensities.

\begin{tabular}{crc}
\hline Curing Units & Manufacturer & Light Intensity \\
\hline Astralis 5 & Vivadent Est. FL-9494 Schaan, Austria & $405 \mathrm{~mW} / \mathrm{cm}^{2}$ \\
Top Light & Hsin-Chuang City, Tiapei, Hsien, Taiwan & $141 \mathrm{~mW} / \mathrm{cm}^{2}$ \\
Ultradent & 505 West 10200 South, South Jordan, Utah 84095 USA & $400 \mathrm{~mW} / \mathrm{cm}^{2}$ \\
\hline
\end{tabular}

Table (2): Restorative Materials Used in This Study.

\begin{tabular}{ccc}
\hline Materials & Manufacturer & Batch No. \\
\hline Point 4 & Kerr, Avenue, Orange, Ca 92867, USA & 31580 \\
Tetric & Vivadent, Schaan, Liechtenstein & C24789 \\
Degufill mineral & Degussa, Hüls AG, Hanau, Germany & 0942 \\
Clearfil (SE Bond) & Umeda, Kita-Ku. Kuraray, Osaka, Japan & Lot 125 \\
\hline
\end{tabular}

No.= number

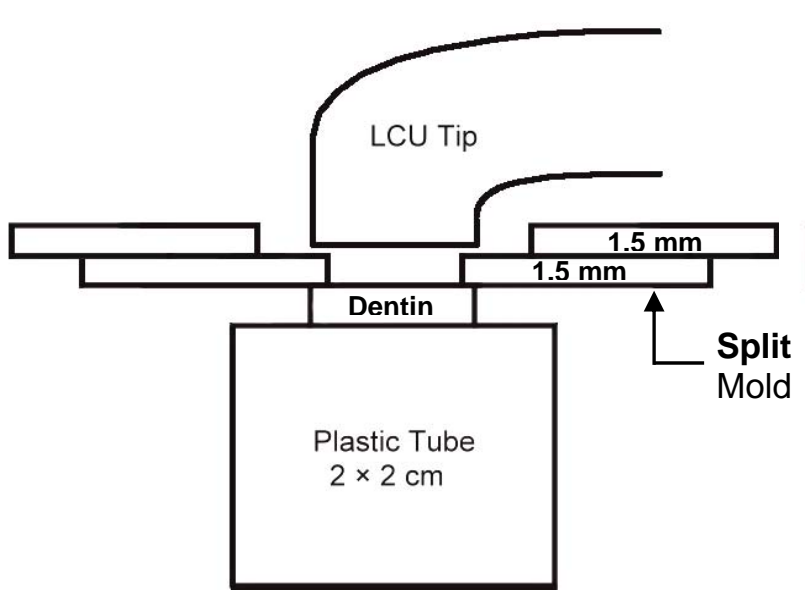

A

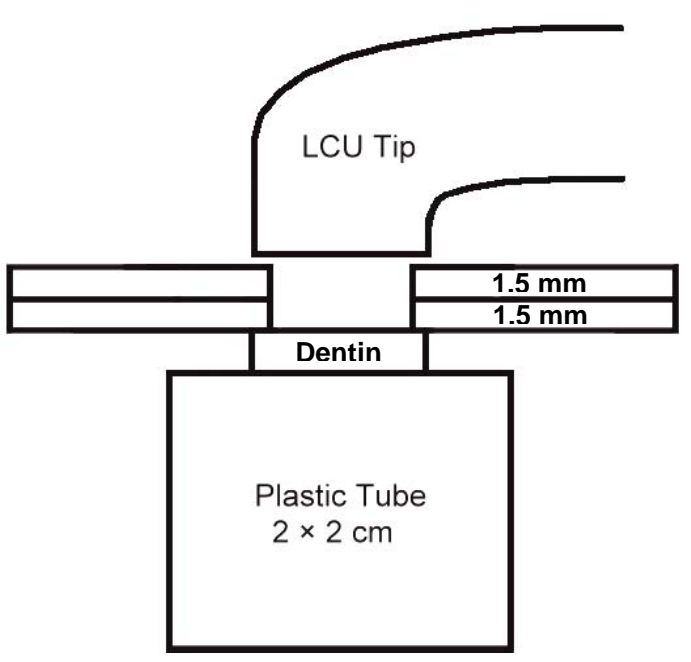

B

Figure (1): A: Split mold at first composite increment application.

B: Split mold at second composite increment application. 


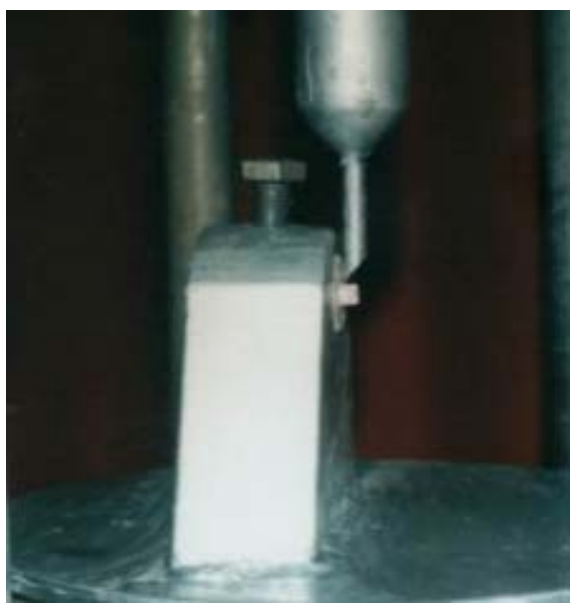

A

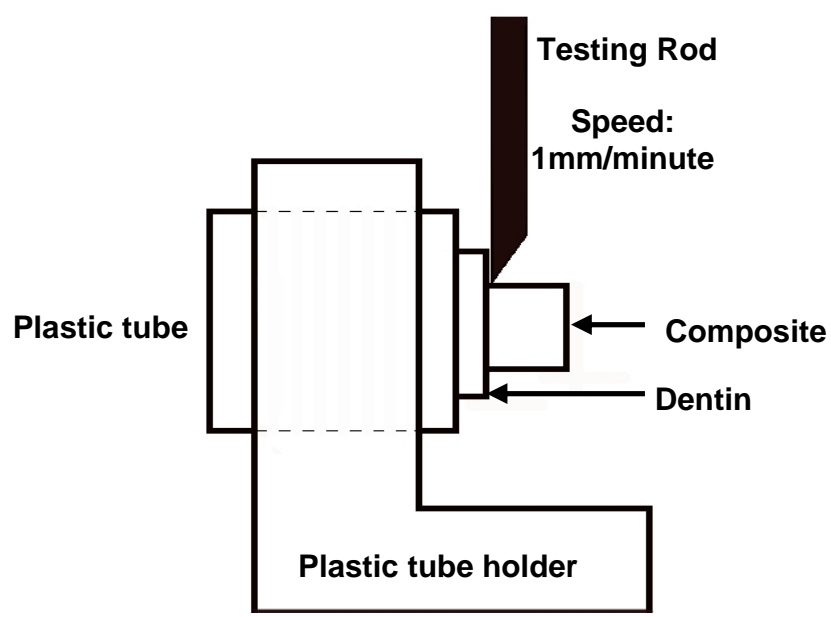

B

Figure (2): The testing rod loading the composite core by Universal Testing Machine.

\section{RESULTS}

Mean and standard deviation of SBS for the tested groups were as listed in Table (3) and represented by a histogram with (Figure 3).

The one-way analyses of variance (ANOVA) was performed to show if there are significant differences between groups, and its revealed that there are significant differences among groups at probability value of $p \leq 0.05$, as shown in Table (4).

Duncan Multiple Range Test revealed that there are no significant differences in SBS among Point $4^{\mathrm{TM}}$, Tetric and Degufill mineral composite types that cured by the same LCU (no significant differences among subgroups belong to same group that cured by same LCU). But, there were significant differences in SBS among groups that cured by different LCUs. The SBS of the three subgroups that cured by high intensity LED were significantly higher than all other subgroups. While the SBS of the three subgroups that cured by QTHLCU were significantly higher than those cured by low intensity LED, as shown in Table (5).

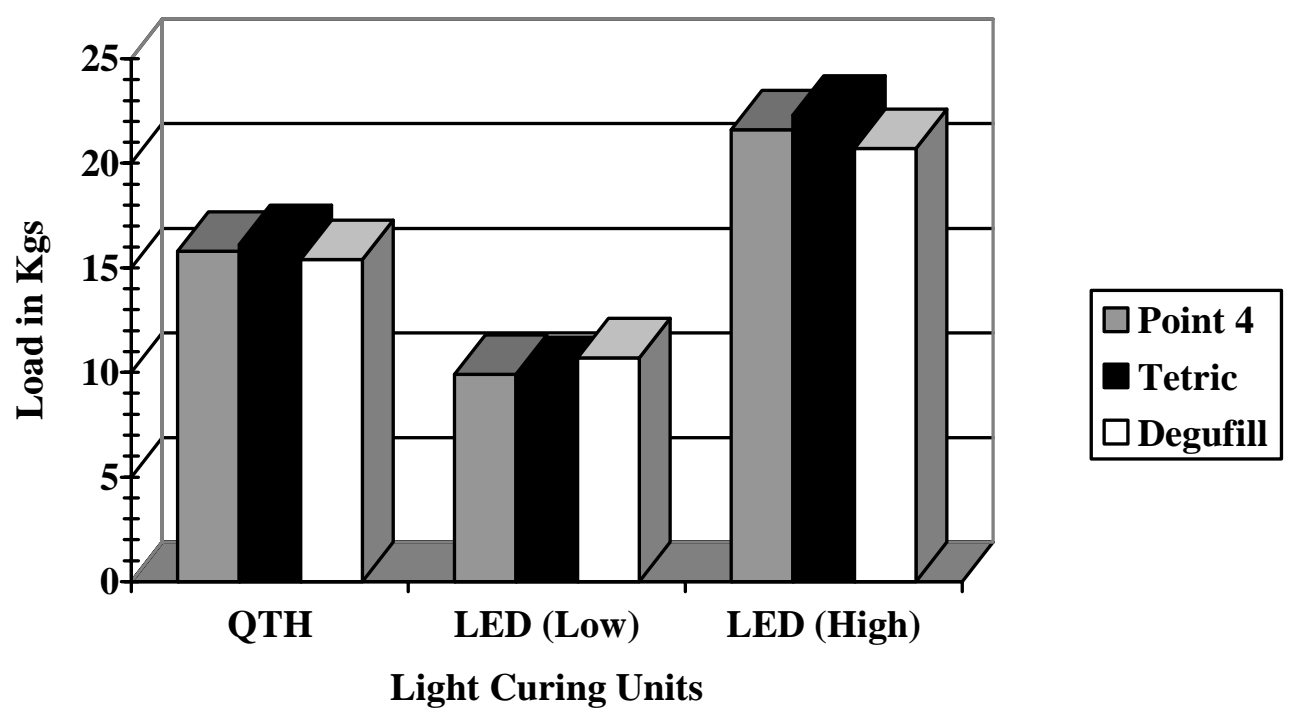

Figure (3): A histogram shows the means of SBS for the tested groups. 
Table (3): Mean and Standard deviation of SBS for the tested groups.

\begin{tabular}{ccccc}
\hline Type of LCU & Type of Composite & No. & Mean (Kg) & + SD \\
\hline QTH & Point 4TM & 10 & 15.8 & 2.6 \\
QTH & Tetric & 10 & 16.1 & 3.2 \\
QTH & Degufill & 10 & 15.4 & 1.3 \\
\hline LED (Low Intensity) & Point 4 ${ }^{\mathrm{TM}}$ & 10 & 9.9 & 2.2 \\
LED (Low Intensity) & Tetric & 10 & 9.8 & 2.6 \\
LED (Low Intensity) & Degufill & 10 & 10.7 & 2.2 \\
\hline LED (high Intensity) & Point 4TM & 10 & 21.6 & 2.7 \\
LED (high Intensity) & Tetric & 10 & 22.3 & 3.1 \\
LED (high Intensity) & Degufill & 10 & 20.7 & 1.8 \\
\hline
\end{tabular}

No.= number of samples; SD= Standard Deviation.

Table (4): One-way Analyses of Variance Test.

\begin{tabular}{cccccc}
\hline & SS & Df & MS & F-value & Significance \\
\hline Between groups & 1171.96 & 8 & 146.494 & 12.121 & $0.000^{*}$ \\
Within groups & 543.87 & 45 & 12.086 & & \\
Total & 1715.83 & 53 & & & \\
* = Significant; SS= sum of squares; Df= degree of freedom; MS= mean square.
\end{tabular}

Table (5): Duncan Multiple Range Test for the tested groups.

\begin{tabular}{ccc}
\hline Type of LCU & Type of Composite & Duncan Grouping* \\
\hline QTH & Point 4 ${ }^{\mathrm{TM}}$ & $\mathrm{C}$ \\
QTH & Tetric & $\mathrm{C}$ \\
QTH & Degufill & $\mathrm{C}$ \\
\hline LED (Low Intensity) & Point 4 TM $^{\text {TM }}$ & $\mathrm{B}$ \\
LED (Low Intensity) & Tetric & $\mathrm{B}$ \\
LED (Low Intensity) & Degufill & $\mathrm{B}$ \\
\hline LED (high Intensity) & Point 4 & $\mathrm{A}$ \\
LED (high Intensity) & Tetric & $\mathrm{A}$ \\
LED (high Intensity) & Degufill & $\mathrm{A}$ \\
\hline * No significant differences in SBS among subgroups with the same letter.
\end{tabular}

\section{DISCUSSION}

The peak of absorption spectrum of the photo-initiator "camphoroquinone" used in light cured dental materials is within the wave length region from $400-500 \mathrm{~nm}$. The most effective wavelength to activate polymerization of these materials is 470 $\mathrm{nm}$ and the most effective wavelength band is in the range $450-490 \mathrm{~nm}{ }^{(20)}$. The spectral output of LED units fall conveniently within this most effective wavelength range, so that no filter required for LED units. LEDs, therefore have the potential to activate the polymerization of dental composites without the drawbacks associated with other types of light curing units ${ }^{(2,10,12)}$.

According to ISO standard (ISO TS 10650, 1999), the acceptable range of light intensity in the range of $400-515 \mathrm{~nm}$ wavelength region is $300-1000 \mathrm{~mW} / \mathrm{cm}^{2}$.
These limit values are standardized for LCUs of halogen type but not for LED units. For LED units, the acceptable light intensities for the same range wavelength is less than $300 \mathrm{~mW} / \mathrm{cm}^{2}$. According to this ISO standardization, intensities of QTH-LCU and both LED units used in this study are within the accepted values.

Since color and translucency of composite material affect depth of cure and some other mechanical properties, one shade was selected for all composite types $(21,22)$. Minimum depth of cure specified in the ISO standard for resin based filling materials (ISO 4049, 2000) was $1.5 \mathrm{~mm}$, the depth of cure for all of the groups exposed to halogen light clearly specified this depth of cure requirement. Although light intensities in the range $400-515 \mathrm{~nm}$ wavelength regions for LED units were 
less than the minimum value of $300 \mathrm{~mW} /$ $\mathrm{cm}^{2}$ specified in ISO standard, the depth of cure exposed to LED units for at least 20 seconds was in excess of $1.5 \mathrm{~mm}^{(4)}$.

Thedegree of polymerization in crosslinked polymeric matrix system plays a potentially significant role in determining the ultimate physical and mechanical properties of the material ${ }^{(13,14,23)}$. Inadequate polymerization results in inferior physicomechanical properties ${ }^{(24-26)}$.

A linear relationship between light intensity and degree of conversion ${ }^{(15)}$ and polymerization contraction has been demonstrated ${ }^{(27)}$. There is a concern that the rapid development of polymerization shrinkage stress, and strain may compromise the formation of an adequate adhesive bond at tooth-composite interface ${ }^{(17)}$. This is clinically important because the integrity of tooth-composite interface is rapidly challenged during the early phase of polymerization when the bond between the hard tissue and composite is still maturing. It has been pointed out that composite cured at lower power density has a better marginal adaptation. But adversely this procedure led to inferior material physical properties. So, it is clearly appeared that higher light intensities has a privilege of improving the mechanical properties of resin composite in spite of the adverse effects of strain produced by high intensities ${ }^{(15)}$.

Actually, polymerization of resin composite is a process mediated by photons. Higher intensity mean larger number of photons per unit time will be delivered into composite activating the sensitive photo initiator complex which give rise to free radical polymerization cascade ${ }^{(28)}$. In the current study, the SBS of QTHLCU and high intensity LED, both were significantly higher than that of low intensity LED. This result indicated that increasng light intensity result in improving the bond strength of resin composite to dentin. This result supported by findings of other studies ${ }^{(29-33)}$.

Temperature rise during polymerizetion and heating from radiation of LED LCUs was significantly lower than QTHLCUs ${ }^{(34)}$. Its speculated that the higher radiation heat result in an additional aceleration of polymerization reaction and consequently produces faster increase in contraction strain ${ }^{(8,16)}$. Shrinkage continues beyond the gel point and in constrained system, even at this early stage of conversion with the week polymeric network structure plasticized by a large excess of free monomer, external stress can begin to be conducted to the bonded interface $^{(35)}$.

Ozturk et al. ${ }^{(36)}$ noted that maximum temperature rise of adhesive resin was $5.16^{\circ} \mathrm{C}$, while the temperature rise of resin composite was only $3.83{ }^{\circ} \mathrm{C}$. these results indicate that the risk of pulpal damage and contraction strain due to elevated temperature should be taken into consideration during photo-polymerization of adhesive resins rather than resin composite. This may be related to the fact that with unfilled resin, there can be a significant exothermic temperature rise that accompanies the rapid polymerization of clinically relevant specimen thickness. In dental composites, the heat rise during cure is moderated by the high proportion of inner filler included $(8,37)$

Studies showed that there were only minor differences in the composite mechanical performance when polymerized with LED-LCUs that had half or less irradiance of QTH-LCUs ${ }^{(2,10,38)}$. These findings not supporting the results of this study, as the SBS of QTH-LCU $\left(405 \mathrm{~mW} / \mathrm{cm}^{2}\right)$ in this study was significantly higher than low intensity LED $\left(141 \mathrm{~mW} / \mathrm{cm}^{2}\right)$. This may be due to fact that light intensities were much higher at those studies (QTH=755 $\mathrm{mW} / \mathrm{cm}^{2}$ and $\mathrm{LED}=350 \mathrm{~mW} / \mathrm{cm}^{2}$ ) (2) compared with this study. This very high light intensity of QTH-LCU will result in excessive temperature rise and subsequent polymerization shrinkage and contraction strain namely during bonding material curing and composite polymerization as well, and this will compromising the bonding quality at tooth-composite interface and this effect counteracting the higher degree of conversion and improvement of mechanical properties of increased light intensity and resulting in SBS comparable to LEDs with lower intensity, as most of the narrower spectral output of LEDs of 440 to $490 \mathrm{~nm}$ fall within camphoroquinone absorption spectrum ${ }^{(2,12)}$. 
However, under the conditions of this study LED provides better SBS compared with QTH-LCU that has the same light intensity.

A reasonable explanation for this event is that the halogen lamp is more efficient in the red and infrared light and is only slightly energetic in the zone of $\mathrm{CQ}$ absorption of maximum at $470 \mathrm{~nm}$. It is common knowledge that red light produces more heat than violet light. This results in temperature rise without signifycant polymerization improvement, while narrow spectrum wavelength of LEDs (about $470 \mathrm{~nm}$ ) don't cause a rise in temperature compared with halogen lamp light, and this narrow spectrum also absorbed more efficiently by CQ that not absorb wave length out of range between 430-500 $\mathrm{nm}^{(7,8,10,39)}$. Over $80 \%$ of the total energy of the halogen lamp were outside the useful curing range. Most of the energy was removed by the interference filter used, only a small fraction of light do actually cure the resin. In contrast $100 \%$ of the light emitted by blue LED lies within the spectrum that can be used to cure resin ${ }^{(9)}$.

\section{CONCLUSIONS}

The shear bond strength of resin composite bonded to dentin is directly proportional with the curing light intensity. The higher shear bond strength obtained by LEDs compared with equivalent intensity QTH-LCUs. Finally the type of resin composite doesn't play important role in shear bond strength when cured by the same light curing unit.

\section{REFERENCES}

1.Nomoto R, Uchida K, Moriyama K, Hirasawa T. Changes in light intensity with time on light curing units. J Japanese Soc Dent Mater Devices. 1998; 17(1): 6266.

2.Jandt KD, Mills RW, Blackwell GB, Ashworth SH. Depth of cure and compressive strength of composite cured with blue light emitting diodes (LEDs). Dent Mater. 2000; 16(1): 41-47.

3.Zach L, Cohen G. Pulp response to externally applied heat. Oral Surg Oral Med Oral Pathol. 1965; 19(4): 515-530.

4.Nomoto R, McCabe JF, Hirano S. Com- parison of Halogen, Plasma and LED Curing Units. Oper Dent. 2004; 29(3): 287-294.

5.Miyazaki M, Hattori T, Ichiishi Y, Kondo M, Onose H, Moore BK. Evaluation of curing units used in private dental offices. Oper Dent. 1998; 23(2): 50-54.

6.Fano L. Ma YW, Marcoli PA, Pizzi S, Fano V. Polymerization of dental composite resins using plasma light. Biomaterials. 2002; 23(4) 1011-1015.

7.Al-Taee AAS. Degree of conversion and curing depth of composite resin. [thesis] College of dentistry, University of Musol. 2006.

8.Hofmann N, Hugo B, Klaiber N. Effect of irradiation type (LED or TQH) on photoactivated composite shrinkage strain kinetic, temperature rise, and hardness. Eur $J$ Oral Sci. 2002; 110(6): 471-479.

9.Kurachi C, Tuboy AM, Magalhaes DV, Bagnato VS. Hardness evaluation of dental composite polymerized with experimental LED-based devices. Dent Mater. 2001; 17: 309-315.

10.Stahl F, Ashworth SH, Jandt KD, Mills RW. Light-emitting diode (LED) polymerization of dental composites: flexural properties and polymerization potential. Biomaterials. 2000; 21(13): 1379-1385.

11.Yoon TH, Lee YK, Lim BS, Kim CW. Degree of polymerization of resin composites by different light sources. $J$ Oral Rehabil. 2002; 29(12): 1165-1173.

12.Mills RW, Jandt KD, Ashworth SH. Dental composite depth of cure with halogen and blue light emitting diode technology. Br Dent J. 1999; 186(8): 388-391.

13.Asmussen E. Restorative Resins: Hardness and strength vs quantity of remaining double bonds. Scandinavian J Dent Res. 1982; 90(6): 484-489.

14.Rueggeberg FA, Craig RG. Correlation of parameters used to estimate monomer conversion in light-curing composite. $J$ Dent Res. 1988; 67(6): 932-937.

15.Uno S, Asmussen E. Marginal adaptation of a restorative resin polymerized at reduced rate. Scand J Dent Res. 1991; 99(5): 440-444.

16.Soh MS, Yap AUJ, Siow KS. Post-gel shrinkage with different modes of LED and halogen light curing units. Oper Dent. 2004; 29(3): 317-324. 
17.Loguercio AD, Reis A, Ballester RY. Polymerization shrinkage: effects of constraint and filling technique in composite restorations. Dent Mater. 2004; 20 : 236-243.

18.Zafer CC, Yazici AR, Akca T, zgünaltay Gül. A morphological and microtensile bond strength evaluation of single-bottle adhesive to caries-affected human dentin after four different caries removal techniques. J Dent. 2003; 31: 429-435.

19. Miyazaki M, Iwasaki K, Onose H. Bonding systems to bovine enamel and dentin. Oper Dent. 2002; 27: 100-104.

20.Nomoto R. Effect of light wavelength on polymerization of light-cured resins. Dent Mater. 1997; 16(1): 60-73.

21.McCabe JF, Carrick TE. Output from visible-light activation units and depth of cure of light activated composites. J Dent Res. 1989; 68(11): 1534-1539.

22.Tsai PCL, Meyers IA, Walsh LJ. Depth of cure and surface microhardness of composite resin cured with blue LED curing lights. Dent Mater. 2004; 20(4): 364-369.

23.Ferracane JL, Greener EH. Fourier transform infrared analysis of degree of polymerization in unfilled resins-methods comparison. J Dent Res. 1984; 63(8): 1093-1095.

24.Vargas MA, Cobb DS, Schmit JL. Polymerization of composite resins: Argon laser vs conventional light. Oper Dent. 1998; 23(2): 87-93.

25.Shortall AC, Wilson HJ, Harrington E. Depth of cure radiation-activated composite restoratives-Influence of shade and opacity. J Oral Rehabil. 1995; 22(5): 337342.

26.Venhoven BA, de Gee AJ, Davidson CL. Polymerization contraction and conversion of light-curing BisGMA-based methacrylate resins. Biomaterials. 1993; 14(11): 871-875.

27.Sakaguchi RL, Peter MC, Nelson SR, Douglas WH, Poort HW. Effects of polymerization contraction in composite restorations. J Dent. 1992; 20(3): 178-182.

28.Stansbury JW. Curing dental resins and composites by photopolymerization. J Est- het Dent. 2000; 12: 300-308.

29.Silikas N, Eliades G, Watts DC. Light intensity effects on resin composite degree of conversion and shrinkage strain. Dent Mater. 2000; 16:292-296.

30.Halvorson RH, Erickson RL, Davidson CL. Energy dependent polymerization of resin based composite. Dent Mater. 2002; 18: 463-469.

31.Emami N, Soderholm K-JM. How light irradiance and curing time affect monomer conversion in light-cured resin composites. J Oral Sci. 2003; 111: 536-542.

32.Georges AJ, Swift EJ, Thompson JY, Heymann HO. Irradiance effects on the mechanical properties of universal hybrid and flowable hybrid resin composites. Dent Mater. 2003; 19: 406-413.

33.Musanje L, Darvell BW. Polymerization of resin composite restorative materials: exposure reciprocity. Dent Mater. 2003; 19: 531-541.

34.Yap AUJ, Soh MS. Thermal emission by different light-curing units. Oper Dent. 2003; 28:260-266.

35.Stansbury JW, Lemon MT, Lu H, Ding X, Lin Y, Ge J. Conversion-dependent shrinkage stress and strain in dental resins and composites. Dent Mater. 2005; 21: 56-67.

36.Ozturk B, Ozturk AN, Usumez A, Usumez S, Qzer S. Temperature rise during adhesive and resin composite polymerrization with various light curing sources. Oper Dent. 2004; 29(3): 325-332.

37.Turssi CP, Ferracane JL, Vogel K. Filler feature and their effects on wear and degree of conversion of particulate dental resin composites. Biomaterials. 2005; 26 : 4932-4937.

38.Oberholzer TG, Du Preez IC, Kidd M. Effect of LED curing on the microleakage, shear bond strength and surface hardness of a resin-based composite restoration. Biomaterials. 2005; 26: 3981-3989.

39.Tarle Z, Meniga A, Knezevic A, Sutalo J, Ristic M. Composite conversion and temperature rise using a conventional plasma arc, and an experimental blue LED curing unit. J Oral Rehabil. 2002; 29: 662-667. 